\title{
Information Technology for Managers: Australian Generic MBA Programs
}

\author{
Stephen Burgess \\ Victoria University of Technology \\ PO Box 14428, MCMC, Melbourne, Australia, 8001. \\ Tel: 61396884353 Fax: 61396885024 \\ Email: Stephen=Burgess@vut.edu.au
}

Arthur Tatnall

Victoria University of Technology

PO Box 14428, MCMC, Melbourne, Australia, 8001.

Tel: 61393652135 Fax: 61393652592

Email:Arthur@cougar.vut.edu.au

\begin{abstract}
There has been a recent increase in the number of MBA programs offered in Australia. Most of these programs offer some type of subject related to information technology in their 'required' curriculum. This paper reviews arguments relating to information technology subject content and reports the results of a study of the opinions of students studying the information technology subject in a generic MBA program.

The evidence indicates that some level of knowledge of information technology is required for MBA students and that there is an increasing emphasis being placed upon the business and management applications of information technology.

A study of students enrolled in the information technology subject as part of the generic MBA at Victoria University of Technology indicated that they do rely on information technology during their course. Respondents indicated that their knowledge of information technology improved whilst studying the subject. The study supported the notion that topics related to business and management applications of information technology are becoming increasingly important to MBA students.
\end{abstract}

Keywords

Computers, information technology, MBA programs; management education

\section{INTRODUCTION}

There has been an explosion in the number of generic MBA programs offered in Australia in the early 1990s. Most of these programs offer some type of subject in information technology to their students. 
This paper briefly reviews arguments relating to the content of information technology subjects in Australian generic MBA programs. It then reports the results of a study of the opinions of students enrolled in the information technology subject in the generic MBA program at Victoria University of Technology.

\section{SETTING THE SCENE}

In 1992, the Australian Federal Government commissioned a study to find out how far formal management education programs on offer contribute to the process of alerting present and future managers to the potential roles of science and technology. The study used MBA programs as the models for management education programs, as the MBA is considered to be a generalist and not specialist qualification (NBEET and DITAC, 1992, p.2). The resultant report revealed that little coherent attention is given to science and technology issues in management education. Encouragement was given for the development of MBA electives which focus on science and technology issues, and encouragement was given to students to study these (NBEET and DITAC).

The report suggested that management education should be used to help repair Australian industries' failure to make better use of scientific and technological resources and that more and better theory concerning such issues would be helpful in their inclusion into management education (NBEET and DITAC).

After three years of investigation, the Australian Industry Task Force on Leadership and Management Skills (headed by David Karpin), released what became known as the Karpin Report in 1995. The driving force behind the initiative was to 'find pathways to lasting change and improvement through seeking enterprise and individual-driven solutions to the problems and challenges facing Australia's business leaders' (Industry Task Force on Leadership and Management Skills, 1995, p.iii).

In both of these reports it is extremely difficult to differentiate between 'science and technology' issues and solely 'information technology' (IT) issues, which are the focus of this paper. However, Recommendation 22 of the Karpin Report relates to curricular in postgraduate and undergraduate management education. A greater emphasis upon IT is recommended to assist in meeting the business needs of the 21 st century. One of the key areas mentioned is the need to improve the strategic skills of managers. This is one area where IT can have an impact in organisations (Industry Task Force on Leadership and Management Skills). Innovations associated with IT can potentially influence choices relating to products and markets (Collins and Devanna, 1992).

\section{THE GENERIC MBA}

This paper examines generic MBA programs as offered by business schools. It does not examine specialist MBA programs, nor programs directly sponsored by corporations.

"An MBA is a postgraduate qualification designed to develop conceptual and practical skills for emerging and practical managers. It is a generalist qualification which provides candidates with competence in a broad range of functional areas considered essential for effective contemporary management" (Burke, 1993, p.35).

Australian business schools offer a range of diverse MBA courses. These are a blend of the American MBA (with a technical approach to management) and the European MBA (with emphasis placed on a more practical approach) (Dwyer and Marshall, 1993). 


\section{INFORMATION TECHNOLOGY IN THE GENERIC MBA}

A case study at the University of California (Frank, 1991) revealed that MBA students lacked knowledge about technical issues, even when directly related to major business issues. Success was eventually gained in teaching technology issues by:

- illustrating technology with actual case study examples where possible

- limiting the amount of time spent elaborating on how the technology works

- treating technology descriptions as footnotes to the central business issue (Frank).

There is an argument that there should be increased emphasis placed upon IT and its role in affecting all aspects of business (Anderson, 1990; Jenkins, 1992).

In fact, the content of IT subjects can differ markedly across various MBA programs. Some of the reasons for these differences are the number of contact hours, the sequencing of the subject in the course and content decisions made by course designers (Silver, Markus and Beath, 1995). Due to the broad range of topics covered in these courses it is unlikely that any of the topics will be covered to any significant depth (Tatnall, Davey and Burgess, 1996).

It appears that general personal computer (PC) skills are taught adequately in most MBAs, either indirectly or as part of the dedicated curriculum. PC laboratory usage is on the increase (LaPlante, 1991). However, PC literacy does not, by itself, provide an adequate understanding of how IT can be effectively used in business. In many cases, graduating students will not be using the technology, but will need to understand how it could be appropriately deployed to solve a business problem (LaPlante). Students should be equipped to understand how to maximise the benefits, avoid the dangers and be aware of the limitations of IT (Silver, Markus and Beath).

A survey by Ramakrishna, Vijayaram and Quarstein $(1995$, p.15) of executives of US employers of MBA students revealed that

'there seems to be a trend away from programming skills and technology and development knowledge, and a movement towards skills in off-the-shelf software and knowledge of information management and other soft areas'.

\section{INFORMATION TECHNOLOGY IN THE AUSTRALIAN MBA}

The NBEET/DITAC report targeted a number of topic areas for inclusion in Australian MBA courses. Of these topic areas, the following were relevant to this paper (that is, they relate to IT issues rather than science or general technology issues):

- models of technology innovation

- methods of acquiring technology (such as inhouse R\&D)

- technology as a component of business plans

- marketing of technology

- globalisation of technology

- technology strategies (such as strategic technology alliances)

- knowledge of library and database services pertaining to current awareness

Many of these subject areas reflect the need to emphasise the business and management applications of the technology, rather than just how to use the technology. 


\subsection{Current offerings}

'A Guide to MBA Programs' has been published for a number of years (Dwyer and Marshall; Clout and Marshall [1995]). The guide shows the institutions offering MBA courses in a particular year. Details of the subject offerings of many of these courses are also offered. Subjects containing a substantial IT component can be readily identified by their title. For instance, subject titles such as Management Information Systems, Information Systems and Computing and Information Systems could be safely identified as having a substantial IT component. It is reasonable to suggest that other subject titles, such as Information Management, also have a substantial IT component.

The following table represents a comparison of these guides for 1994 and 1996 course offerings. Each MBA was classified according to its identifiable IT subject offerings.

Table 1. Information Technology in Australian Generic MBAs: 1994-1996

\begin{tabular}{lcc}
\hline Category & 1994 & 1996 \\
\hline A. Compulsory IT unit(s) and IT electives available & 9 & 9 \\
B. Compulsory IT unit(s) but no IT electives & 12 & 12 \\
$\quad$ available & & \\
C. No Compulsory IT unit but IT electives available & 7 & 9 \\
D. No obvious IT offering & 0 & 1 \\
E. Unsure/ No subject detail provided & 4 & 3 \\
\hline Total & 32 & 34 \\
\hline
\end{tabular}

There has been little change over the two year period. Over $60 \%$ of all generic MBA courses contain a compulsory IT subject. The majority of the others provide an IT elective. This shows that the majority of institutions offering generic MBAs recognise the importance of providing at least basic IT knowledge to the MBA graduate.

\section{VICTORIA UNIVERSITY OF TECHNOLOGY STUDY}

The subject BGP6503 Management Information Systems has been taught in the MBA at Victoria University of Technology since the course was introduced in 1992. In that time lecturers involved in the subject (including both authors) have had three major goals:

- to provide students with adequate PC literacy skills, so that they may complete their course and feel comfortable using a PC after its completion

- to provide students with a basic understanding of the roles of IT personnel (such as systems analysis and design and programming), so that they may interact with these personnel in their future employment

- to provide students with a basic understanding of the contribution (strategic or otherwise) that IT can make to the business.

Students in the subject BGP6503 were asked to complete a questionnaire related to the subject. There were 24 questionnaires handed out and all were returned. Not every respondent completed every question. 


\subsection{Demographics}

\section{Discipline areas}

Respondents were requested to indicate the discipline area(s) in which they possessed previous qualifications before commencing the course. Many respondents indicated more than one area. In this case the response was shared between the two areas.

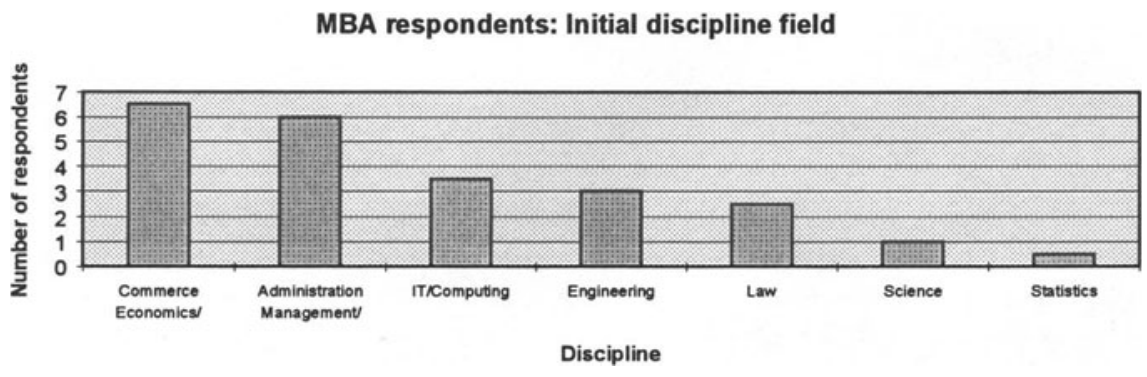

Figure 1 Initial discipline field

This graph indicates the diverse nature of the backgrounds of students studying the program, and supports Burke's comments relating to the generalist nature of the MBA.

\section{Hours/week computer use}

Respondents were asked to indicate the number of hours per week that they used computers during the course.

MBA Respondents: Weekly Computer Usage

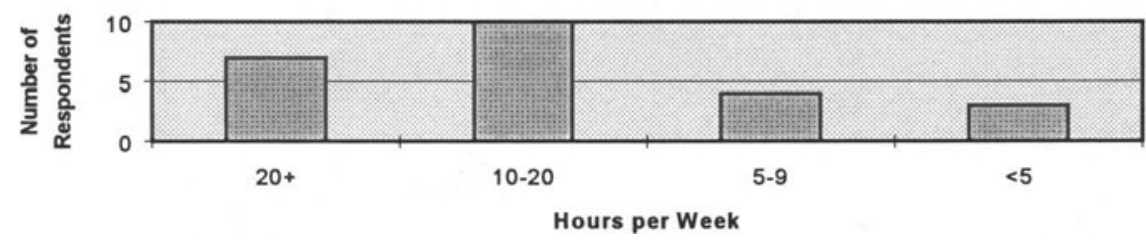

Figure 2 Weekly Computer Usage

Some $70 \%$ of students used the computers for more than 10 hours per week. This reinforces the need to provide at least basic PC competency skills to MBA students.

\subsection{Results}

\section{Knowledge of IT}

Respondents were requested to indicate (using a Likert scale) their knowledge of IT before commencing the MBA course and after the subject BGP6503 was studied. 
MBA Respondents: Knowledge of IT

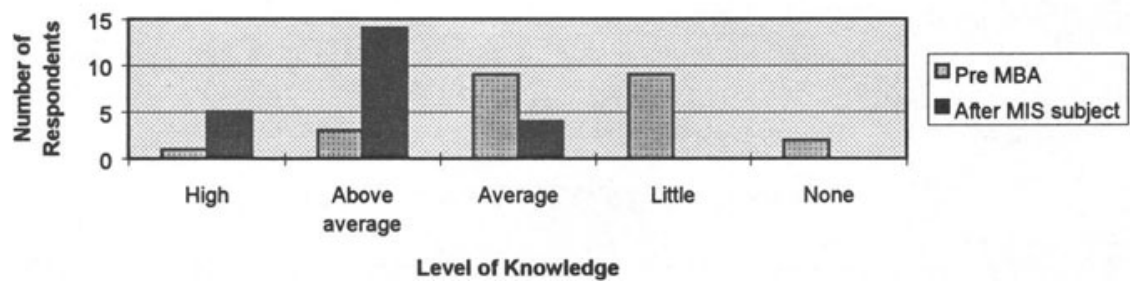

Figure 3 Knowledge of IT before and after BGP6503

This result seems to be a rather good advertisement for the subject! Of the 24 responses, 23 indicated an improvement in their knowledge of IT ( the 24th circled 'High' before and after). In general terms, the majority of respondents indicated 'average' or 'little' knowledge of IT before commencing the MBA course, and the majority indicated 'high' or 'above average' knowledge after completing BGP6503.

It is recognised that the reference base for 'high' or 'little' levels of IT knowledge may be different amongst students. Even taking this into account, the vast majority indicated an increased level of IT knowledge at the conclusion of the subject.

\section{Application Package Use}

Respondents were requested to estimate their level of usage of different packages in laboratories. These responses were totalled and averaged.

MBA Respondents: Average \% Application Usage

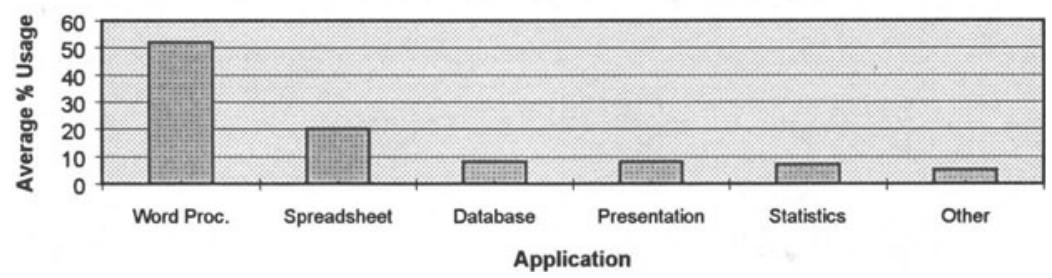

Figure 4 Average application usage (\%)

The overall result was not very surprising. Word processing was the main application used (just over half of the time). In reality, this probably more reflects effort devoted to assignment preparation rather than future intended usage in business. It may also explain the high levels of laboratory usage indicated earlier. It would be interesting to pursue this area further.

\section{Topics}

Respondents were requested to indicate the relative level of importance of certain topic areas covered in the subject BGP6503. The choice was again represented as a Likert scale, with ' 1 ' representing 'Most Important' and '5' representing 'No Importance'. Results for each topic area were summed and averaged, resulting in a weighted mean. 
Table 2 Importance of IT Topic Areas to MBA Students: Weighted Means

\begin{tabular}{lc}
\hline Topic Area & Weighted Average \\
\hline Project Management & 1.96 \\
Management of Information Technology & 1.96 \\
Information Technology Planning & 2.00 \\
Systems Analysis and Design & 2.08 \\
Purchasing/ Justifying Information Technology & 2.48 \\
Programming & 2.78 \\
\hline
\end{tabular}

The first four topics were rated between Most Important and Some Importance. A number of respondents ranked 'Purchasing/Justifying IT' and 'Programming' close to 'No Importance', although they still rated as being of at least 'Some Importance' overall. It is probably fair to say that students generally support the idea that the planning and management issues related to IT are important, as suggested earlier.

\section{FURTHER STUDIES}

It would be interesting to further examine the IT offerings of the various Australian institutions that offer generic MBA programs. In particular it would be interesting to compare the allocation of resources devoted to:

- basic PC literacy skills

- more technical skills

- business and management topics.

Another interesting follow up area would be to examine the allocation of time that students spend in laboratories during their MBA studies. How much of this time is allocated to assignment preparation (say, in using a word processor to prepare a paper)? How much is allocated to the use of packages to further their knowledge of the use of IT for the potential business manager?

\section{CONCLUSION}

The evidence indicates that some level of knowledge of IT is required for MBA students. The vast majority of Australian institutions offering generic MBA programs require their students to complete an IT unit. There is still some conjecture as to what equates to suitable content in such a subject, although there is some indication that there is an increasing emphasis being placed upon business and management applications of information technology.

A study of MBA students at Victoria University of Technology showed that they do rely on IT during their course, although the reasons for this were not investigated. Respondents indicated that their knowledge of IT improved during the course of studying the subject. The study supported the notion that topics related to business and management applications of information technology are becoming increasingly important to MBA students. 


\section{REFERENCES}

Anderson, Gordon 'A Fresh Approach to the MBA', Industrial and Commercial Training, Vol.22, No.1, 1990, pp.28-31.

Burke, Kerry 'MBA Investment reaps big rewards in marketplace', The Australian Financial Review, Management Education Survey, 14 September 1993.

Clout, Jason and Marshall, Kate MBAs in Australia: A Guide to Graduate Management Education, Financial Review Library, Victoria, 1995.

Collins, Eliza G.C. and Devanna, Mary Anne 'Management by Interaction', Modern Office Technology, Vol.37, Iss.5, May 1992, pp.14-15.

Dwyer, Michael and Marshall, Kate Guide to MBA Programs in Australia, Australian Financial Review Library, Victoria, 1993.

Frank, Dr. Howard 'Teaching Technology and Business Lessons', Networking Management, Vol.10, Iss.10, September 1992, pp.84-86.

Industry Task Force on Leadership and Management Skills, Enterprising Nation: Executive Summary, Australian Government Publishing Service, Canberra, 1995.

Jenkins, Roger L. 'A New Era in MBA Education: Tennessee's Leadership Role', Survey of Business, Vol.28, Iss.1, Summer 1992, p.2.

LaPlante, Alice 'Making the Grade', Infoworld, Vol.13, Iss.6, February 1991, pp.50-52.

National Board of Employment, Education and Training (NBEET) and the Department of Industry, Technology and Commerce (DITAC), Science and Technology Issues in Management Education, Australian Government Publishing Service, Canberra, October 1992.

Ramakrishna, Hindupur V., Vijayaraman, Bindiganavale S. and Quarstein, V.A., 'Executives Speak Out on MBAs' Competency in Information Technology', Journal of Systems Management, March/April, 1995, pp.14-17.

Silver, Mark S., Markus, M Lynne and Beath, Cynthia M. 'The Information Technology Interaction Model: A Foundation for the MBA Core Course', MIS Quarterly, September 1995, pp.361-390

Tatnall Arthur, Davey Bill and Burgess Stephen Management Information Systems: An Introduction, 3rd. Edition, Data Publishing, Victoria, 1996.

\section{BIOGRAPHY}

Stephen Burgess is a senior lecturer in Information Systems at Victoria University of Technology. His teaching and research interests centre around the area of information management. He lectures in this area to computing and management students.

Arthur Tatnall is a senior lecturer in Information Systems at Victoria University at Technology. His research interests include information systems curriculum development, visual programming and project management. He lectures in systems implementation, management information systems and visual programming to computing and management students. 